\title{
Incursões em outridades com Calvin e Haroldo
}

\author{
Priscila Pesce Lopes de Oliveira ${ }^{1}$
}

$\underline{\text { http://lattes.cnpq.br/3255751515717967 }}$

Enviado em: 21/11/2018

Aceito em: 21/12/2018

\begin{abstract}
Resumo: O artigo aproveita um ferramental de crítica literária e algumas considerações de Derrida para abordar as tirinhas "Calvin e Haroldo", de Watterson. Inicia com breve discussão do estatuto da literatura infantil para os estudos literários. A seguir, explora algumas particularidades e potencialidades das crianças e dos animais como personagens, bem como a relação estabelecida entre os protagonistas na série homônima. Finaliza considerando o interesse da ficção como modalidade de incursão por outridades, especialmente na chave do humor, tom que modula e tem o condão de dispor favoravelmente quanto ao inesperado e ao diferente.

Palavras-chave: Calvin e Haroldo; Literatura infantil; literatura e outras linguagens; alteridade.
\end{abstract}

Abstract: This paper uses literary criticism tools and Derrida's thoughts on animality to study Watterson's "Calvin and Hobbes" comics. The first section briefly discusses literary studies approaches to children's literature. The following sections explore some particularities and potentialities of children and animals as characters, as well as the relationship between the main characters in their namesake series. At the end, I consider how fiction may help us experience otherness, especially when using humor, which modulates discourse and usually presents the unexpected and the different in a favorable light.

Keywords: Calvin and Hobbes; Children's literature; literature and other languages; otherness.

\section{Tesouros possíveis}

- Por que está cavando esse buraco?

- Estou procurando algum tesouro enterrado.

- E o que você encontrou?

- Algumas pedras imundas, uma raiz esquisita e um monte de larvas nojentas.

— Logo na primeira tentativa??

(Bill Watterson, Existem tesouros em todo lugar)

"Existem tesouros em todo lugar", explica o garoto de seis anos Calvin a Haroldo, seu amigo tigre. O diálogo se dá em uma tirinha publicada diariamente em jornais nos Estados Unidos entre 1985 e 1995, escrita e desenhada por Bill Watterson. O efeito humorístico é obtido com o emprego de uma das estratégias mais recorrentes para este fim, a quebra de expectativas (RAMOS, 2010, 2011). As expectativas que pré-condicionam a aproximação dos fenômenos muitas vezes constituem filtros nos quais alguns aspectos da experiência se perdem ou são afastados do campo de considerações. Foi o que se deu, por algum tempo, com a literatura infantil, território neblinoso para a teoria e a crítica literárias.

${ }^{1}$ Doutoranda em Letras pela Universidade Federal do Ceará. E-mail: priscilapesce@gmail.com

https://periodicos.unifap.br/index.php/letras

Macapá, v. 8, n. 4, $2^{\circ}$ sem., 2018 


\section{Uma larva nojenta: o estatuto incerto e movente da literatura infantil}

Tentativas de conceituação da literatura infantil defrontam-se com um objeto especialmente irrequieto e escorregadiço, na medida em que sua definição conjuga duas outras bastante instáveis: a de literatura e a de criança. Os pesquisadores que têm se acercado da literatura infantil são unânimes em caracterizar como historicamente flutuantes tanto a denominação quanto o conjunto de textos que ela designa, uma designação que trabalha em três eixos: a escrita dirigida a jovens leitores, a atividade editorial que orienta os textos a um determinado público leitor, por vezes independentemente do projeto do escritor e mediante estratégias diversas (como as adaptações que reduzem a extensão e simplificam o léxico e sintaxe das obras), e o contato das crianças com o texto, seja diretamente ou por intermédio de um adulto que lê em voz alta. O papel desses mediadores não necessariamente é negativo, uma vez que podem marcar a atividade da leitura como uma experiência afetiva e prazeirosa e, como aponta Nières-Chevrel (2009, p. 30), no mais das vezes é na literatura infantil que se constroem os alicerces da experiência dos livros e que se fazem leitores para toda uma vida. Contudo, vemos que a criança aparece como polo integrante desses processos mas é detentora de pouca autonomia quanto à seleção dos textos cujo contato lhe é viabilizado; as decisões nesse sentido passam por diversas figuras e instâncias, como editores, escolas [ou seja, o Governo (LAJOLO, 2010, p. 106)], professores, pais etc.

Subjacente ao sistema de múltiplas tutelagens está a concepção da criança como um ser em formação, e correspondentemente o cunho formativo ou didático prevaleceu nos textos voltados ao público infantil ao longo dos séculos XVIII, XIX e parte do XX. A própria nomenclatura é bastante esclarecedora nesse sentido: Nières-Chevrel (2009, p. 14-15) conta que na França sob o império napoleônico fixou-se a classificação editorial "livros de educação", que logo passou a conviver com "livros de criança" e, em seguida, "literatura infantil". Esse deslizamento terminológico cartografa mudanças de enfoque, da finalidade ao uso e à natureza.

O caráter funcional de formação entra em conflito direto com um dos atributos reivindicados como literários por excelência a partir de meados do século XIX: a intransitividade. A visão da criança como uma versão menor do adulto, com toda a conotação negativa e limitadora desse adjetivo, estende-se aos textos que lhe seriam próprios. Nas palavras de Peter Hunt, a partir da suposição amplamente disseminada de que "a apreciação estética não seja algo disponível à criança (...) a definição "não-funcional" de "literatura" exclui toda literatura infantil ou não se aplica a ela” (2010, p. 85). Para o crítico inglês, o alijamento da criança do plano estético desenrola-se sobre a percepção de que os procedimentos e estruturas mais adequados ao registro infantil seriam limitados, sem que se dê ao trabalho de, como sugere Nières-Chevrel (op. cit., p. 24) e foi cabalmente demonstrado, por exemplo, pelas produções do grupo francês OuLiPo, imaginar que restrições podem ser bastante produtivas em se tratando de literatura.

Da extensa discussão sobre as especificidades da literatura infantil, gostaríamos de nos deter no ponto que acena a nosso objeto de estudo: a presença e importância das imagens nos livros destinados a e aproveitados por crianças. 


\section{Um buraco a cavar: tirinhas e literatura infantil}

Em sua comunicação "Fronteiras da Literatura: poesia, mídia, cinema" apresentada na Abralic em 2010, Adalberto Müller sustenta o interesse de se movimentar as fronteiras epistemológicas dos estudos literários:

Fronteira e nomadismo, assim, impõem um modelo de pensamento marcado pela hibridação e pelo movimento. Uma recusa da pureza concomitante com uma recusa da estabilidade; uma aceitação do diverso casada com uma compreensão do movimento das coisas. No caso da Literatura, creio que se pode pensar a poesia e a narrativa como linhas imaginárias, como lugares de passagem (...). É preciso pensar a literatura não como estrutura fechada e autossuficiente (inclusive para o ato da leitura apenas), mas como estrutura que se abre para a passagem. (MÜLLER, 2011, p. 169)

Uma das propostas da Literatura Comparada é abordar as zonas de confluência entre a literatura e outras paragens, sejam os chamados gêneros de fronteira (como os paratextos e correspondências), outras áreas do conhecimento ou mesmo outras linguagens. Longe de ser um céu de brigadeiro, essas confluências têm trechos revoltosos - que aliás costumam mostrar-se bastante profícuos em termos de análise e reflexão. Nessa linha, propomos aqui aproveitar algum arcabouço crítico e teórico da literatura infantil para pensar a constituição das personagens Calvin e Haroldo e de sua relação nas tirinhas homônimas.

De acordo com Ramos (2013), as tirinhas podem ser consideradas um subgênero discursivo pertencente ao gênero histórias em quadrinhos. $\mathrm{O}$ pesquisador recorre a Bakhtin para pensar os gêneros como dotados de uma estrutura composicional, formada de elementos recorrentes ou regulares e outros livres, e a Maingueneau, para quem o suporte e o contrato comunicativo também são pertinentes para pensar o conceito de gênero. Dentro da tipologia proposta pelo brasileiro, Calvin e Haroldo seriam considerados tirinhas cômicas: peças no formato quadrinhos, de curta extensão (em geral com três ou quatro quadros), publicação periódica, apresentando personagens fixos, com predomínio de sequências narrativas e diálogos e de um tom humorístico, obtido a partir de um desfecho inesperado (RAMOS, 2010-11, p. 57). O formato quadrinhos implica a presença de desenhos que figuram os personagens, cenários e outros elementos narrativos.

Diversos estudos dedicados à literatura infantil apontam a grande presença e a importância da ilustração nesse gênero (Cf. NIÈRES-CHEVREL, 2009, p. 18; LAJOLO, 2010, p. 102; GREGORIN FILHO, 2010, p. 21 ss), afirmada inclusive pela própria Alice que, sonolenta, observa a irmã absorta a ler e pergunta-se, aborrecida, "Para que pode servir um livro sem figuras nem conversas?” (CARROLL, 1982, p. 11). Para nossos propósitos, retomaremos essa discussão nos termos de Gregorin Filho, para quem a obra literária infantil é frequentemente multimodal, combinando as linguagens verbal e imagética. Nesse quadro, cabe à ilustração importante papel significante na obra e o desempenho de uma série de funções, das quais destacamos três que acreditamos estarem presentes também nas tirinhas: descritiva, que descreve personagens, objetos, cenários; expressiva, que configura traços da "postura, gestos e expressões de personagens e outros elementos"; e narrativa, a qual tem seu ponto alto "nos livros em cuja construção se utiliza apenas a ilustração para contar uma história” (GREGORIN FILHO, 2010, p. 23).

Com efeito, verifica-se em muitas obras voltadas a crianças mais novas uma equipresença de texto e imagem, ou mesmo a predominância desta na área das páginas, junto a blocos diminutos de palavras. Nas tirinhas, a linguagem imagética tem maior destaque e o 
texto aparece no mais das vezes como diálogo, monólogo interior ou onomatopeias, e a própria entonação pode ser comunicada graficamente: é comum que gritos sejam apresentados em balões de contornos espinhentos ou grafados com letras maiores e estilizadas, enquanto os pensamentos têm um estilo de balão próprio, em formato de nuvem.

A copresença de imagem e texto e a pequena extensão são duas das configurações materiais que favorecem a orientação/oferta tanto de tirinhas quanto de obras literárias infantis a pré-leitores e leitores iniciantes ${ }^{2}$, dentre eles as crianças, que aparecem como destinatário privilegiado mas não exclusivo desses textos. Guardadas as devidas diferenças, parece-nos possível uma aproximação das tirinhas Calvin e Haroldo com um ferramental de investigação literário, sobretudo se nos propusermos um percurso concentrado em áreas comuns a ambos os gêneros discursivos, como as personagens.

\section{A aventura do desconhecer: crianças e animais como incursões em outridades}
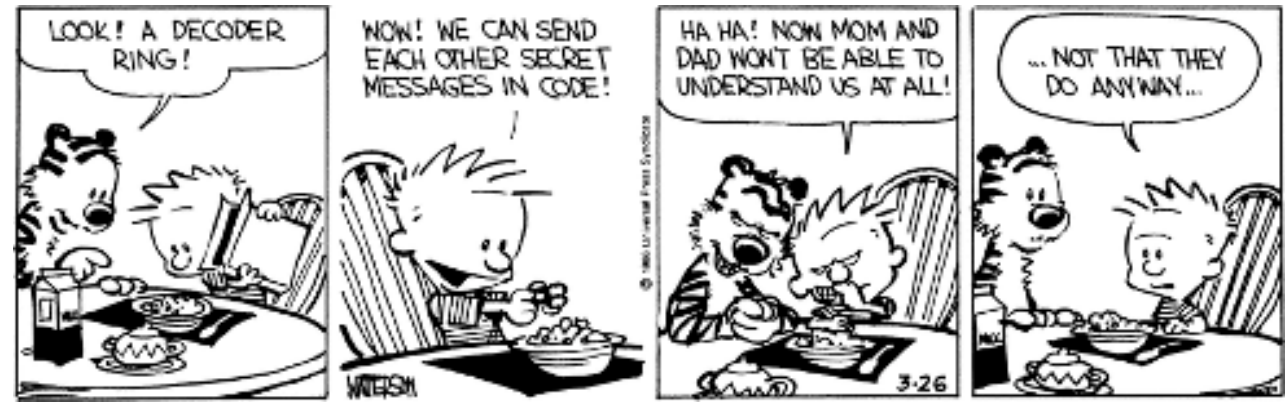

Figura 1: Anel decodificador

Fonte: WATTERSON, B. 26 de março de 1986. Disponível em: < http:/ /www.gocomics.com/calvinandhobbes/1986/03/26>. Acesso em: 21 set. 2018.

Tradução:

Quadro 1: "Olha! Um anel decodificador!"

Quadro 2: "Uau! Podemos trocar mensagens secretas em código!"

Quadro 3: "Ha ha! Agora a mamãe e o papai não vão conseguir entender a gente!’

Quadro 4: “... Não que eles consigam, de qualquer modo...”

A tirinha da Fig. 1 brinca com a sensação bastante difundida de uma certa opacidade entre crianças e adultos. Contrariando o que seria de se esperar a partir da noção de crianças como adultos reduzidos/simplificados, seu funcionamento interior não é imediatamente acessível, a despeito do suposto desenvolvimento superior dos mais velhos. Em contraste com personagens infantis que, em termos de temperamento e comportamento, são duplos miniaturizados de adultos, a chamada para uma entrevista com Watterson enfatiza que Calvin "age como uma criança de verdade" (WATTERSON; CHRISTIE, s/d, trad. livre), colocando essa verossimilhança como um grande feito do cartunista.

Em grande parte, os comportamentos de Calvin percebidos como "realistas" são posturas e atitudes que o distanciam de personagens infantis modelares, os quais ocupam

${ }^{2}$ classificação de Nelly Novaes Coelho retomada por Gregorin Filho (2010), p. 21. 
muitas páginas da literatura infantil por conta do cunho didático do gênero que discutíamos anteriormente - sobre este ponto, Nières-Chevrel (2009, p. 23) destaca a aprovação em 1949 de uma lei francesa proibindo a edição de quaisquer materiais para crianças em que fossem representados favoravelmente a prática de crimes, delitos ou ações contrárias à moral e aos bons costumes, como "a mentira, o roubo, a preguiça”, entre outros. Por sua vez, Calvin é teimoso, insubordinado, egoísta e preguiçoso - além de amoroso, curioso, vivo e criativo; em suma, apresenta uma ampla gama de comportamentos humanos, não apenas a seleção do que seria mais desejável de se cultivar nos seres em formação. Poderíamos mesmo pensar que ele se inscreve, ao lado de Alice, Peter Pan, Mowgli e outros, em uma segunda linhagem literária: a das "crianças turbulentas" (PRINCE, 2015, p. 98). Essa tumultuosidade torna um tanto difícil o relacionamento de Calvin com vários dos adultos importantes em sua vida, como seus pais e sua professora:
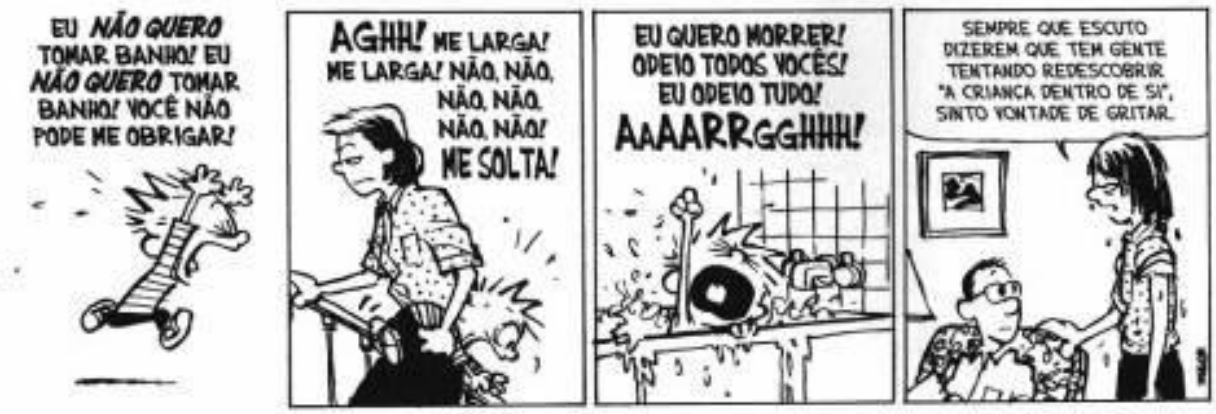

Figura 2(a)
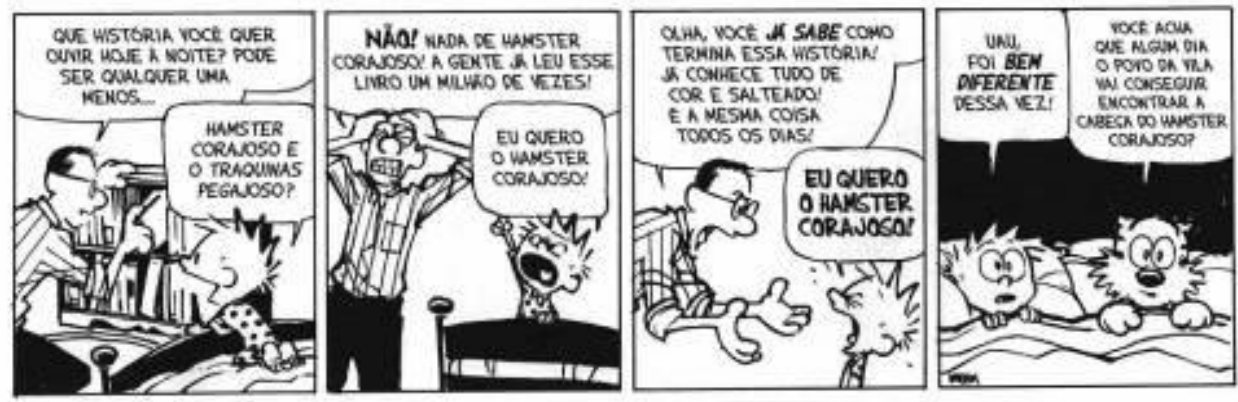

Figura 2(b)

Fonte: Watterson (2011), p. 145(a) e 159(b).

Os constantes conflitos dizem de uma certa distância entre a criança e os adultos que a cercam, um distanciamento bastante curioso se considerarmos que todos os adultos já foram, um dia, crianças, e deveriam portanto conseguir se colocar sem problemas no lugar dos pequenos, ainda que a operação oposta fosse menos simples. Todavia, a nosso ver, esse hiato tão espinhoso pode ser também fonte de uma rica experiência: a da abertura para a outridade, tanto a intransigentemente obtusa do outro quanto aquela que é constituinte de nós mesmos, ponto em que se cruzam algumas das trajetórias de crianças e de animais na literatura.

Uma disposição curiosa e hospitaleira para com o outro vem na contracorrente de boa parte do empenho civilizatório radicado na tradição greco-judaica; Jacques Derrida e Judith Butler são dois dos muitos nomes da filosofia das décadas finais do século XX a reconhecer 
a exclusão do diferente como dinâmica operante no que se pode chamar, grossíssimo modo, do projeto essencialista de si, lençol freático de conceitos como o humano e a subjetividade. Pautado em uma supervalorização da razão, esse projeto humano a que Derrida chamará logocêntrico rebaixa a subumano, inumano ou ahumano todos os entes percebidos em diferentes graus como desarrazoados, dentre os quais mulheres, crianças, animais e, ao longo da empresa colonial europeia, grupos humanos inteiros. Nessa perspectiva ciumenta do que lhe considera próprio, o outro é visto como uma ameaça da qual é preciso distinguir-se nitidamente sob o risco de se tornar, também, abjeto (BUTLER, 1993, p. 48-49); a esse outro não cabe o status de sujeito, e tal coisificação subjaz a uma série de práticas sociais exclusionárias por meio das quais esconjura-se a fragilidade da subjetividade pela afirmação da potência dos sujeitos.

Essa desconsideração dos desiguais nem sempre toma formas agressivas; o assujeitamento pode dar-se não como sujeição, mas como um pouco caso do olhar: "a filosofia talvez o esqueça, ela seria mesmo esse esquecimento calculado, [o animal] pode, ele, olharme. Ele tem seu ponto de vista sobre mim. O ponto de vista do outro absoluto" (DERRIDA, 2002, p. 28). De tão incomum, essa equiparação dos pontos de vista chega a ter efeito cômico, como se vê na seguinte tirinha:

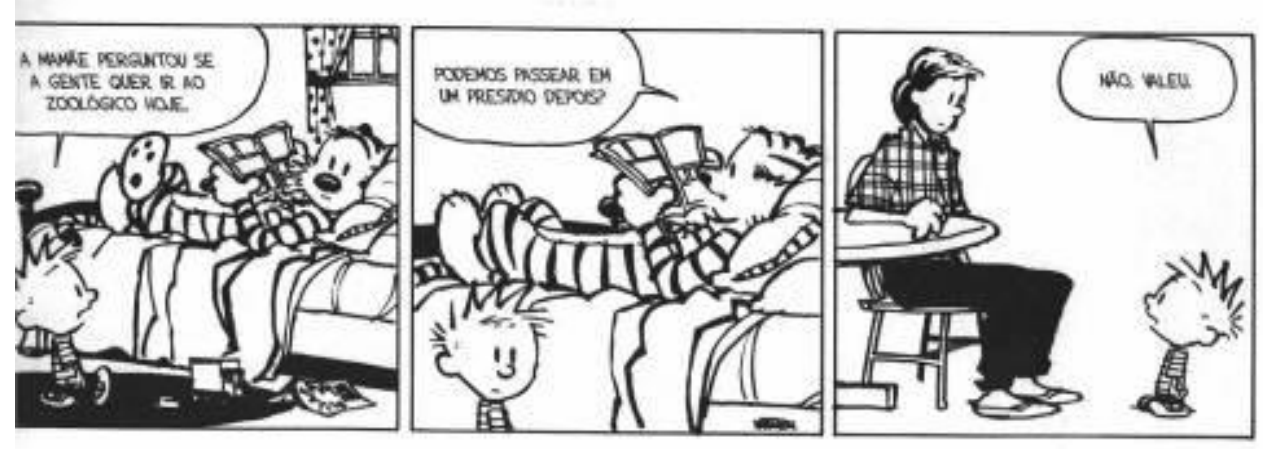

Figura 3: Visita ao zoológico

Fonte: Watterson (2013), p. 19.

A tirinha da Fig. 3 cruza os dois modos de assujeitamento que comentávamos: o pouco peso dado à qualidade de vida dos não-humanos possibilita que seja considerado aceitável mantê-los em condições extremamente desconfortáveis para proporcionar um divertimento ocasional - privilegiando nossos interesses menores sobre seus interesses maiores, nos termos de Peter Singer (2010, p. 270). Vale notar que atualmente o propósito dos zoológicos passa por transformações com vistas a torná-los espaços de preservação de espécies ameaçadas e/ou recuperadas de condições ainda mais precárias, como cativeiros particulares, circos etc.; contudo, seu uso principal ainda é o entretenimento, o que diz muito da ausência dos animais na esfera de consideração moral humana.

No caso das crianças, à semelhança do que ocorreu com as mulheres por muitos séculos, pode tratar-se de, a pretexto de proteger suas "sensibilidades delicadas", negar-lhes na ficção todo um espectro de temas relativos a emoções e experiências tidos como impróprios mas que fazem parte da vivência humana, como a tristeza, a solidão, o luto, o desespero, o sofrimento e a morte. A idealização age como apequenamento e recusa à representação cultural dos "outros" a complexidade, acabando por, como nota Nières-Chevrel (2009, p. 23), configurar uma literatura mentirosa no silenciamento das agruras. Felizmente, essa tendência não soube ser total; há mesmo um topos de personagens infantis que enfrentam todo 
tipo de dificuldades e privações (rapidamente, podemos pensar em Oliver Twist, de Dickens; Cosette e Gravroche, de Hugo; Zezé, de José Mauro de Vasconcelos; os Capitães da Areia, de Amado), mais frequentes nos escritos dirigidos a adultos e que contemporaneamente tem ganhado também as páginas da literatura infantil (como Harry Potter, de Rowling, e os irmãos Baudelaire, de Snicket). No caso de Calvin, apesar de a personagem não se defrontar com circunstâncias muito duras, há diversas tirinhas em que suas aproximações a determinados registros são censuradas; o caso mais frequente é o dos bonecos de neve, com os quais ele monta cenas violentas de desmembramentos, decapitações e atropelamentos, além figuras monstruosas (WATTERSON, 2013, p. 81, 87-88, 101, 131, 139 passim). Isso lhe vale repreensões da parte de seu pai, revidadas por Calvin com irreverência:

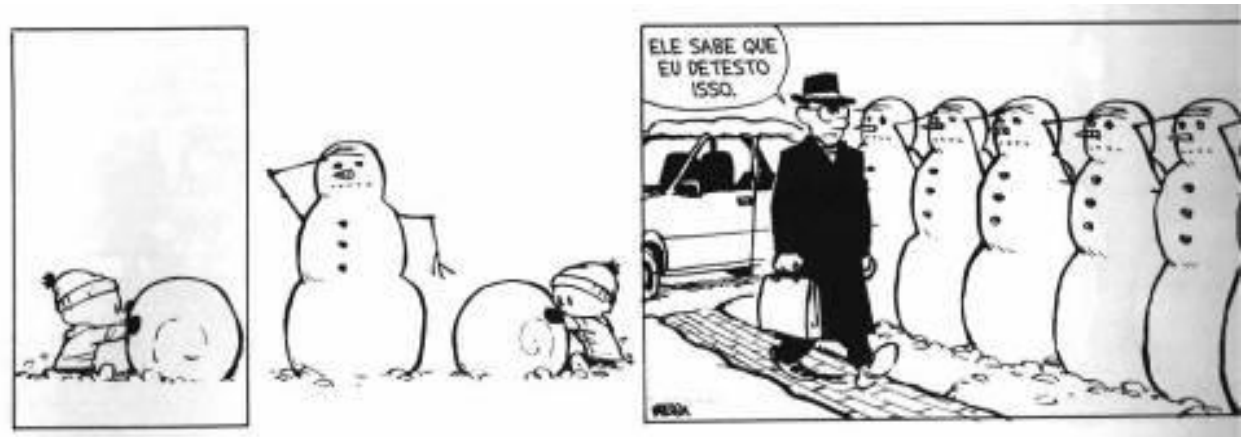

Figura 4: Continência

Fonte: Watterson (2011), p. 28.

O lugar de autoridade do pai é contestado na Fig. 4 por meio de outro recurso cômico, o do exagero. Outro cerceamento que Calvin constantemente busca contornar é o da linguagem:
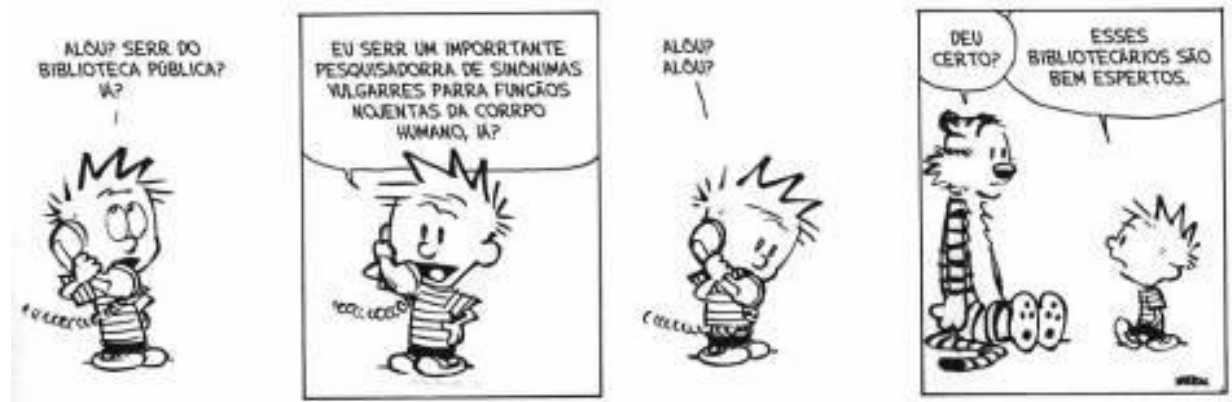

Figura 5: Sinônimos vulgares para funções nojentas

Fonte: Watterson (2011), p. 95.

No caso da tirinha da Fig. 5, Calvin está tentando aprender palavrões. Algo semelhante acontece em outra tirinha, em que Calvin telefona para a biblioteca municipal tentando descobrir o significado de uma palavra. Ele explica ao atendente: "Bom, o problema é justamente esse. Eu não sei como se soletra, e sou proibido de dizer essa palavra"; e, no quadro seguinte, "Você podia me falar todos os palavrões que tem aí e eu aviso quando chegar a... alô??” (WATTERSON, 2011, p. 49). Em ambos os casos, a tentativa de armar-se para uma transgressão linguística é barrada, circunscrevendo as possibilidades de atuação simbólica 
da criança dentro de um limite prescrito e pré-aprovado por instâncias tutelares. Em outras tirinhas, Calvin se apropria de discursos de saber, mas que em sua boca não encontram legitimidade e são descartados ou driblados por seu pai ou pela professora.

A consideração das crianças como seres dotados de complexidade desemboca numa questão de que passamos ao largo ao comentar anteriormente as dificuldades da definição de literatura infantil: a infância como multiplicidade. Múltiplas experiências, contextos, sensibilidades e configurações biopsicossociais ensejam uma infinidade de posturas, comportamentos, disposições, aventuras e desventuras. O agrupamento conceitual sob o singular "criança" opera de maneira muito semelhante ao longamente denunciado por Derrida na primeira parte da conferência $\mathbf{O}$ animal que logo sou (a seguir), acerca do uso de "animal" para designar uma gama de seres viventes bastante diversos entre si (2002, p. 61 ss.).

Para o filósofo argelino, tal agrupamento antropocêntrico opera claramente pela via do não-eu, na tentativa de demarcar uma fronteira nítida entre o ser humano e demais viventes. Os critérios mais comuns evocados para essa distinção estão ligados à capacidade humana de raciocinar, ou de ter consciência de si, ou de ser dotado de linguagem, como fica evidenciado pelo nome científico escolhido para rótulo taxonômico da espécie humana: Homo sapiens sapiens. As exatas características consideradas exclusivas dos humanos são tidas como o ápice do processo evolutivo - ou da criação divina, conforme as preferências cosmogônicas de cada um -, em procedimento tautológico denunciado por diversas vozes, dentre elas a do tigre Haroldo:

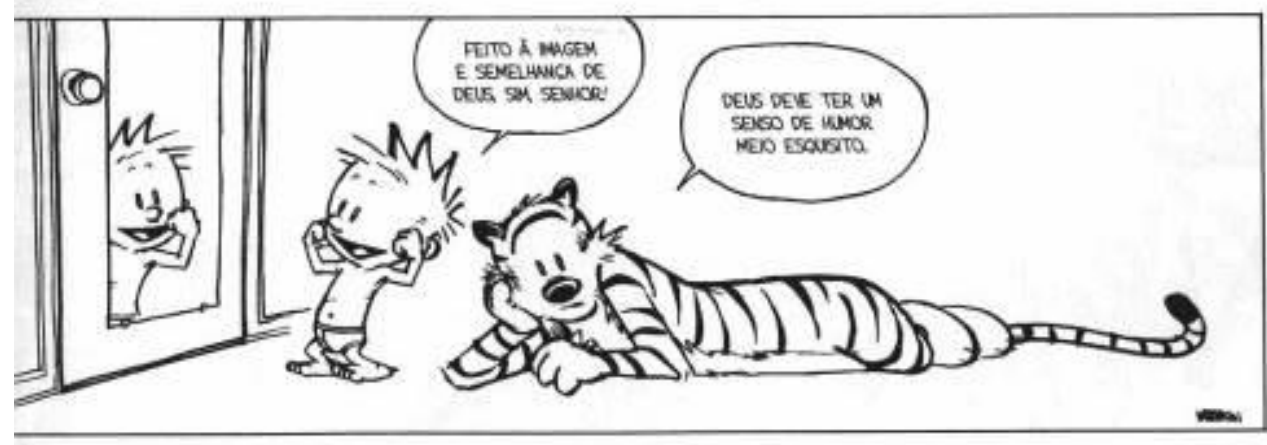

Figura 6 (a)
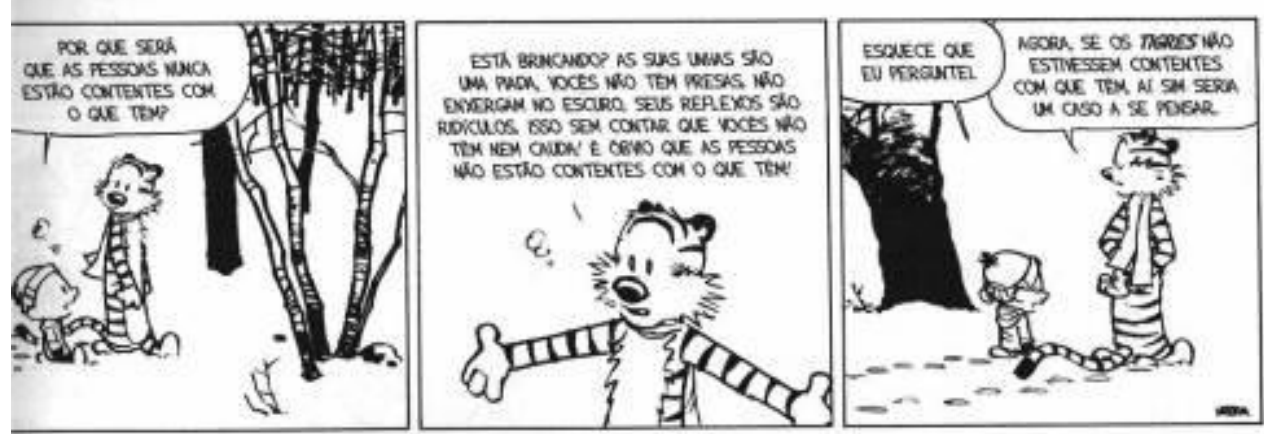

Figura 6 (b)

Fonte: Watterson (2013), p. 31(a) e 157(b).

Haroldo é um tigre visto por outras pessoas como um brinquedo e, na experiência de 
Calvin, seu melhor amigo. Possivelmente, a mesma indiferenciação nada razoável de Calvin entre o real e o imaginário que lhe dá acesso à companhia de Haroldo permite-lhe franquear as barreiras entre o ser humano e o ser outros: há diversas tirinhas em que ele é representado graficamente como animais (mosca, pulga, tiranossauro), sempre contando com um quadrinho no final com a presença/perspectiva dos pais, que enquadra essa incursão como puramente imaginativa (WAT'TERSON, 2011, p. 24, 97 e 102).

O mesmo recurso gráfico-narrativo é usado para Haroldo, que nas interações com os pais de Calvin aparece como um bicho de pelúcia, e portanto inanimado. Contudo, em diversas tirinhas Calvin parece sofrer os efeitos bastante reais das ações de Haroldo, estabelecendo um estatuto ambíguo para o personagem tigre: por exemplo, Calvin costuma ficar todo esfolado e desconjuntado depois de levar um dos inúmeros botes que Haroldo lhe dá como boas-vindas à casa depois da escola. Outro ponto que contribui para colocar em dúvida a personalidade de Haroldo como mera manifestação da imaginação de Calvin - e portanto a ele subordinado - são as ocasiões em que o tigre detém conhecimentos que excedem os do garoto, como no painel a seguir:

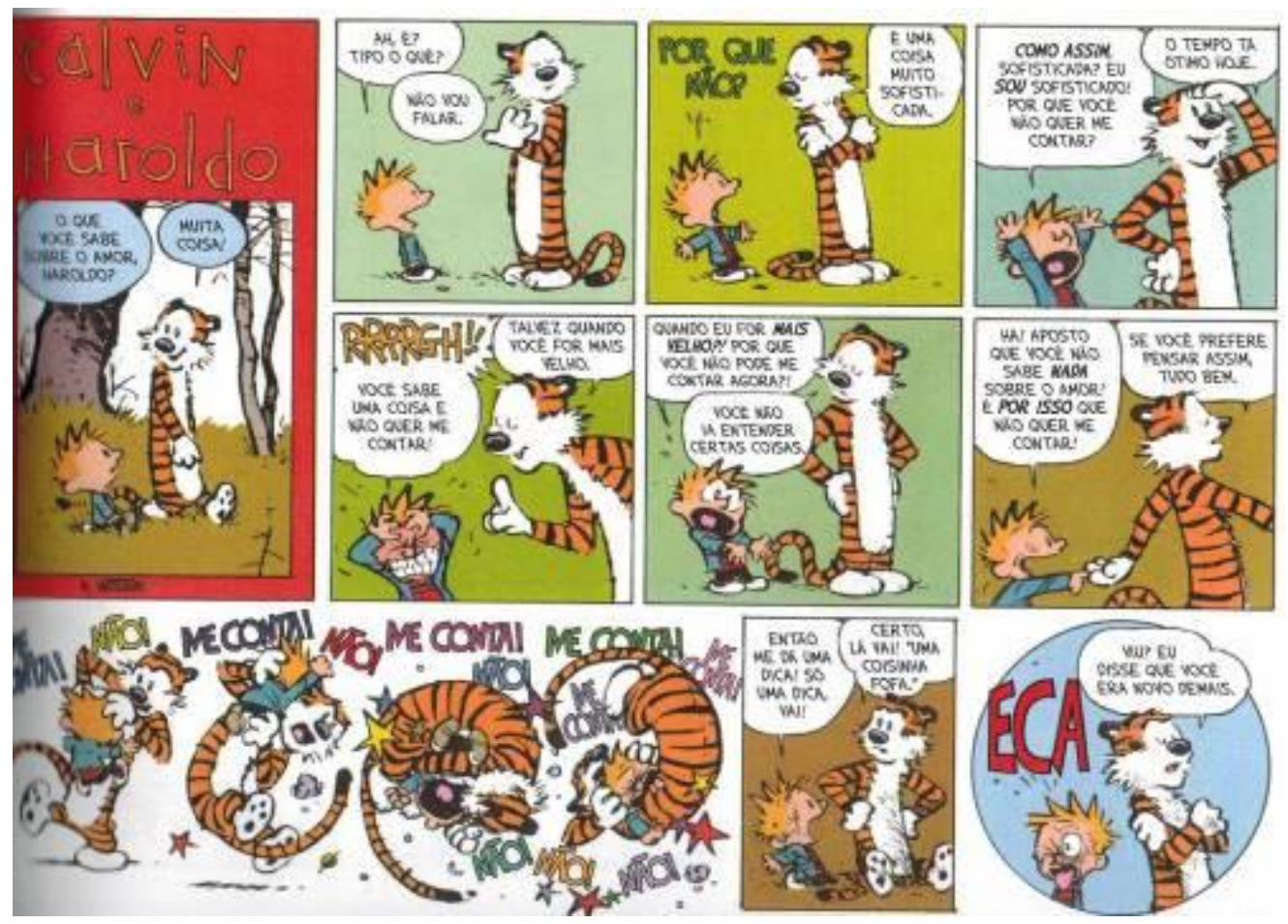

Figura 7: Sobre o amor

Fonte: Watterson (2011), p. 39.

Além de estarem fora do domínio de Calvin, os conhecimentos de Haroldo sobre o amor são de um tipo bastante específico e que nos permite abordar outra característica importante da personagem: seu perfil híbrido, a meio caminho entre animal humano e nãohumano. $\mathrm{Na}$ tirinha da Fig. 7, Haroldo desempenha um papel análogo ao de um irmão ou primo mais velho provocando Calvin. Ele anda com postura ereta, tem acesso à linguagem - apesar de só conversar com Calvin - e discute com desenvoltura todo tipo de assunto, sendo mesmo responsável por algumas das reflexões filosóficas mais memoráveis da série. Haroldo manifesta perfeitamente o ponderado por Prince quanto a uma recorrente 
antropomorfização de personagens animais na literatura infantil: "Essa animalidade aparece de tal forma desanimalisada, que podemos nos perguntar a vantagem de uma tal representação residual do animal. Se esse animal tem tudo de homem, por que não é homem de uma vez?”; ela mesma responde a seguir: "justamente, parece que o animal se identifica simbolicamente a um outro do homem-adulto, como pode sê-lo a criança" (PRINCE, 2015, p. 94, trad. livre). Essa outridade partilhada pode forjar uma aliança pois, diferentemente do visto na Fig. 1: Anel decodificador acerca das dificuldades de comunicação entre Calvin e seus pais, ele e Haroldo se entendem muito bem:
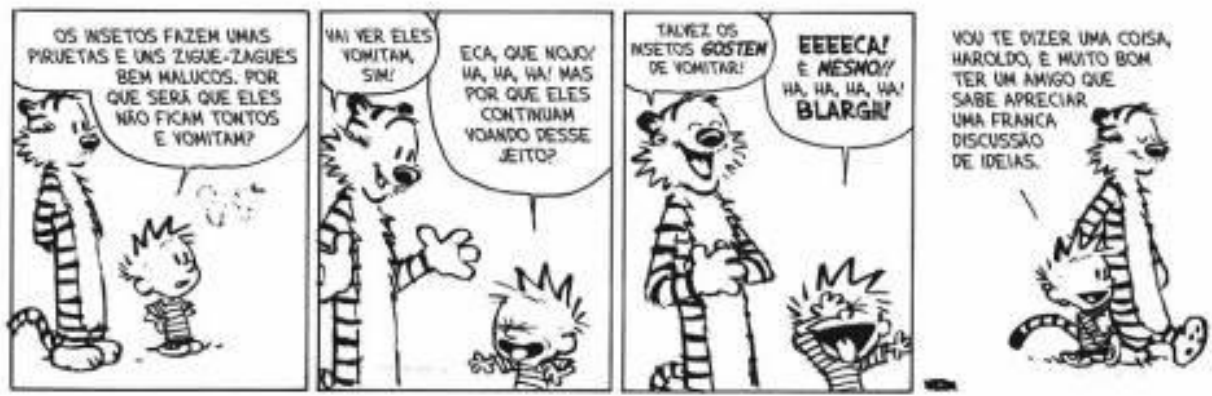

Figura 8: Uma discussão franca

Fonte: Watterson (2011), p. 111.

Tampouco há transparência total: além de conhecimentos tipicamente considerados exclusivos dos humanos, Haroldo apresenta outros tantos saberes e atitudes que lhe são próprios enquanto propriamente tigre, e que Calvin recebe com estranheza ou até receio:
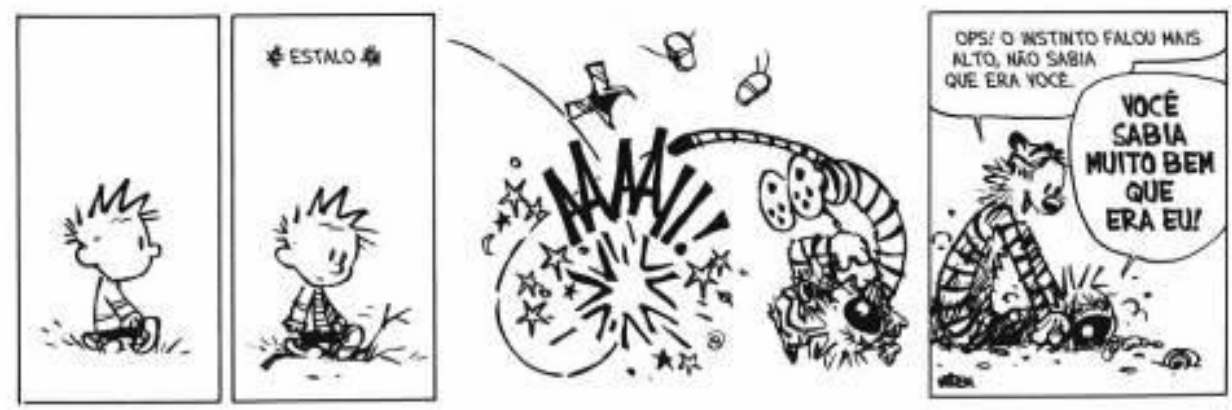

Figura 9 (a) 


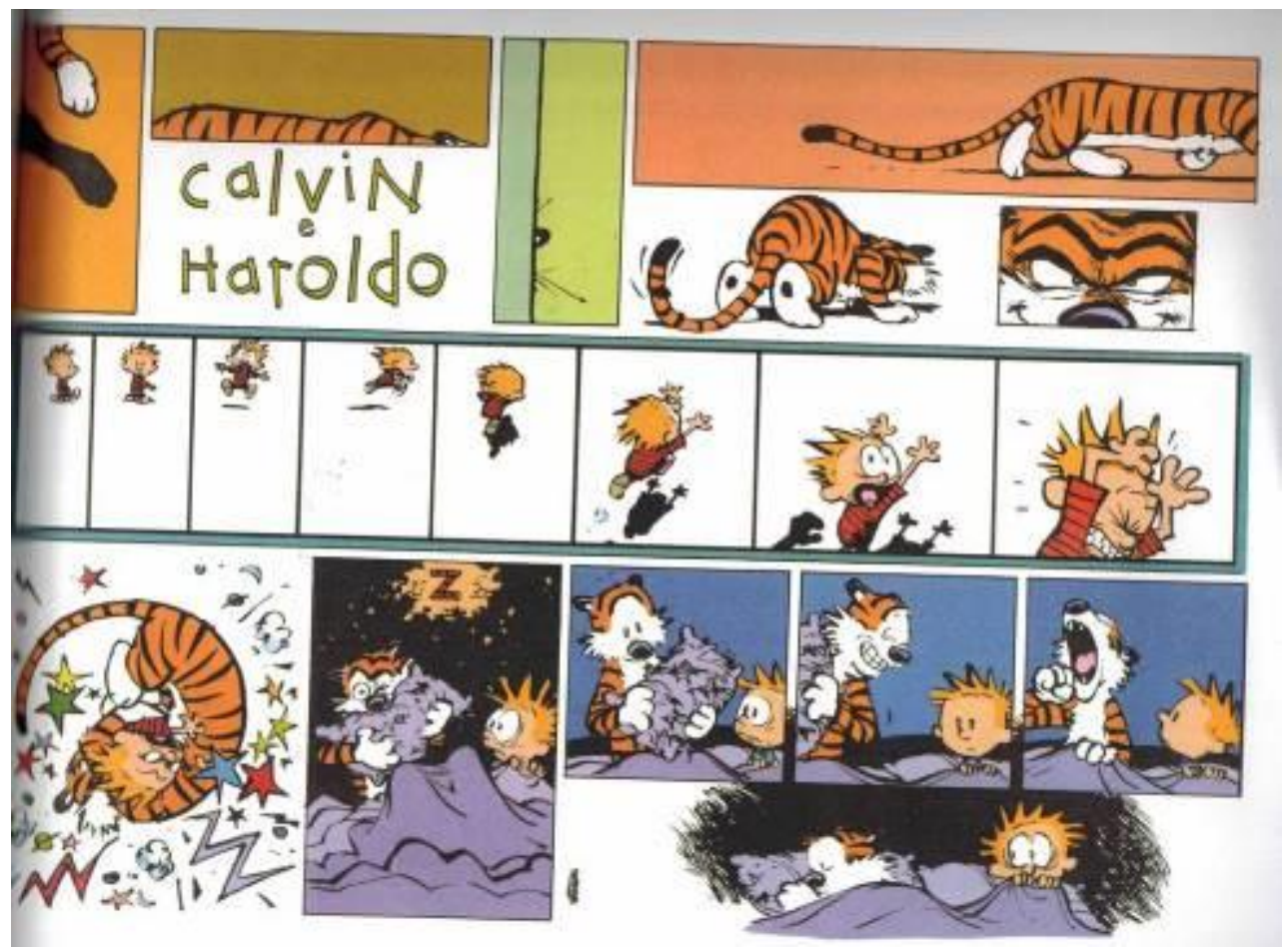

Figura 9 (b)

Fonte: Watterson (2013), p. 42(a) e 47(b).

A convivência de instinto, preferências/uma perspectiva não-antropocêntrica e atributos humanos contribuem para que consideremos Haroldo um personagem muito interessante para pensar a intermitência como uma forma promissora de incursão em outridade, cujo hibridismo ou oscilação agem na chave do humor para tornar o diferente atrativo sem cair na exotização. Da mesma forma, a atitude de Calvin diante da diferença do amigo varia bastante, encaminhando um contato matizado que, em lugar de ignorar ou idealizar a diferença em bloco, abre-se para a complexidade de cada acontecimento. Sendo ou não Haroldo uma criação de Calvin, parece-nos que sua caracterização participa do esforço zooliterário identificado por Maciel, em que poetas buscam:

(...) apreender, pela palavra articulada, o "eu" dos animais não humanos, entrar na pele deles, imaginar o que eles diriam se tivessem o domínio da linguagem humana, encarnar uma subjetividade possível (ainda que inventada) desses outros, conjeturar sobre seus saberes acerca do mundo e da humanidade. (MACIEL, 2011, p. 95)

A partir dessa abertura não isenta de conflitos, é sobre a relação de Calvin e Haroldo que nos deteremos a seguir.

\section{A amizade e o jardim, dois territórios nada funcionais}




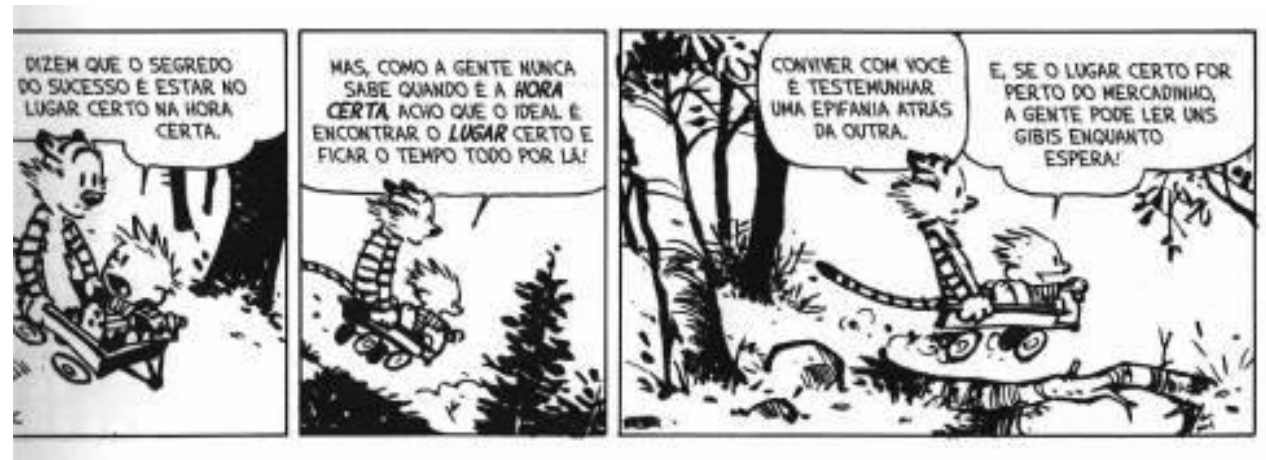

Figura 10

Fonte: Watterson (2011), p. 11.

Boa parte das aventuras de Calvin e Haroldo se passam no jardim, um lugar-comum da infância figurada na literatura conforme Marie-José Chombart de Lauwe, para quem esse espaço de natureza familiar "faz parte da vida imaginária da criança [que o preenche] de todas as criações de sua vida imaginária" (LAUWE, 1991, p. 268). O jardim frequentado por Calvin está possivelmente nos arredores de um bosque, uma vez que é uma área bastante ampla para propriedade privativa, incompatível com a renda classe-média da família. Aventurando-se na natureza, Calvin passeia, desce barrancos com seu carrinho, acompanhado do fiel copiloto tigre; encontra insetos, sapos, pássaros e outros animais (que são desenhados em estilo realista, sem os traços cartunizados de Haroldo, que o aproximam de Calvin, e não conseguem falar a mesma linguagem do garoto), inventa suas próprias versões de esportes como baseball e futebol americano, faz-se explorador e pirata, entre outras brincadeiras.

O jardim/bosque configura assim um ambiente de liberdade, onde Calvin fica à vontade para fazer o que preferir longe do olhar, da temporalidade e das normas dos adultos condições que vemos como cruciais na contraposição com as viagens de acampamento com os pais, em que Calvin não vê a hora de voltar para casa (e para a televisão). Lauwe (1991, p. 271) observa que o jardim estaria, como a criança, no polo da natureza e em inadequação ao mundo dos homens; corroborando essa perspectiva, o duplo monstruoso do jardim de Calvin é justamente a escola, ambiente de controle em que o tempo se arrasta, não há companheirismo e todas as demandas parecem inúteis ou incompreensíveis. Não por acaso, é na escola que Calvin incorpora com maior frequência seu alter-ego Cosmonauta Spiff, desbravando mundos desconhecidos e povoados por alienígenas monstruosos prontos a infligir-lhe as maiores torturas enquanto lhe perguntam as respostas do dever de casa (WATTERSON, 2013, p. 114, 164, passim).

A escola é também o tempo/espaço de ausência de Haroldo. A convivência da dupla se dá principalmente nos ambientes da casa e do jardim, onde brincam, formam clubes exclusivos, disputam guerras de balões d'água, tiram sonecas, discordam e divertem-se. Ainda pensando com Lauwe (1991, p. 291), frequentemente na literatura infantil o animal personagem não é apenas amigo, mas iniciador: facilita a tomada de consciência da criança, partilhando um sistema moral de valores. Na relação entre Calvin e Haroldo, porém, como temos visto, o tigre oscila entre aliar-se ao garoto e fazer-lhe um contraponto, muitas vezes estando próximo do que seria considerado uma postura socialmente desejável, como nas diversas ocasiões em que lembra ao amigo que ele deveria fazer o dever de casa antes de sair para brincar, ou ao invés de procurar evitar a tarefa desagradável por meio de estratagemas elaborados cuja elocubração já é em si uma brincadeira. 
Vemos assim que Haroldo é menos impulsivo e autocentrado do que seu amigo humano, muitas vezes ponderando implicações éticas e sem papas na língua para apontar o que considera tolices de Calvin. Há uma rugosidade da relação dos dois, que comporta tanto companheirismo e auxílio mútuo quanto numerosos desentendimentos, que vão desde brigas pelo cobertor até outras com causas mais sérias, como a que podemos ver na Fig. 11, e aprendizados, como o da Fig. 12:
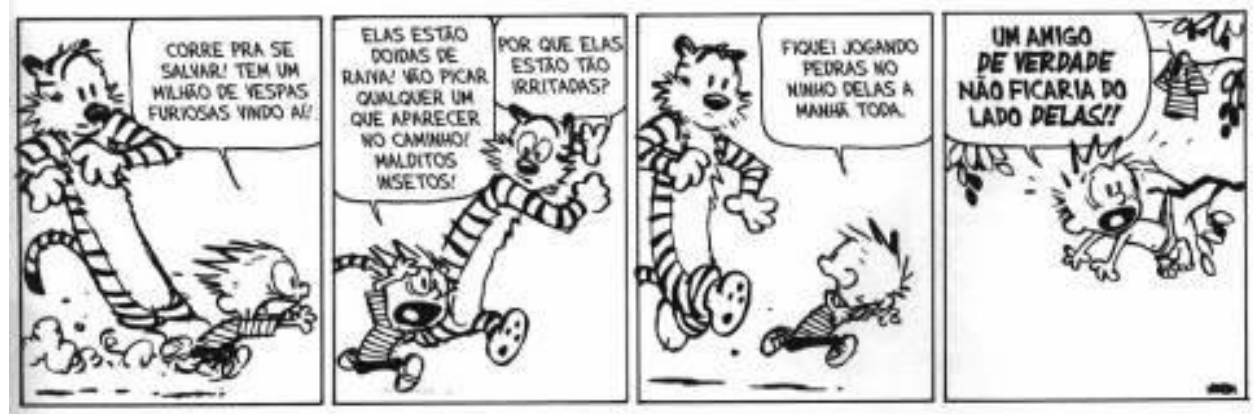

Figura 11: Vespas

Fonte: Watterson (2011), p. 129.
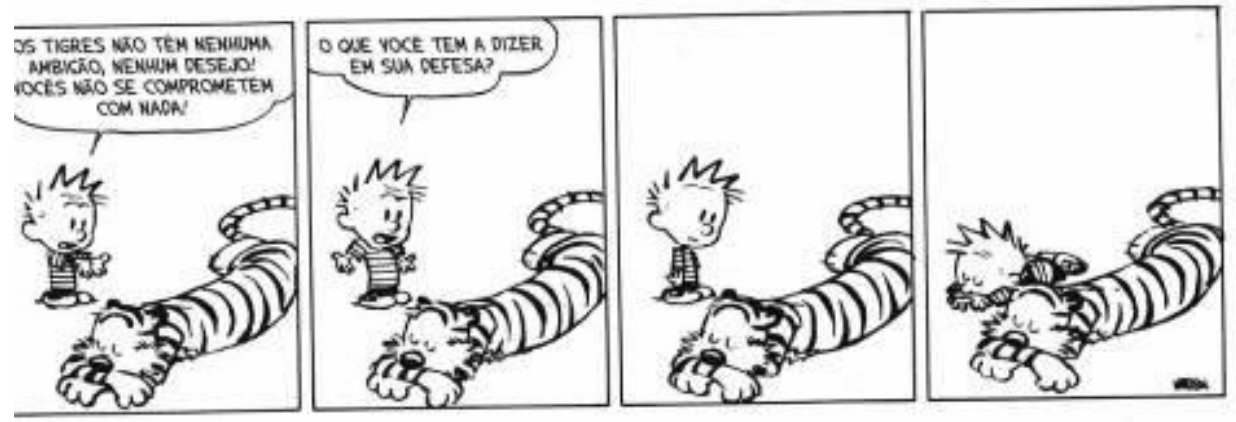

Figura 12: Ambição

Fonte: Watterson (2011), p. 59.

$\mathrm{Na}$ tirinha da Fig. 11, Haroldo assume para si retribuir as ações insensíveis de Calvin para com as vespas, colocando-se momentaneamente do lado dos outros animais não-humanos na fronteira movediça e múltipla comentada por Derrida. Isso nos parece sintomático de uma horizontalidade na relação entre Calvin e Haroldo, algo diverso dos parâmetros de convivência entre bicho de estimação e dono, uma das configurações mais presentes da dupla humano/não-humano na literatura infantil. Sendo Haroldo um amigo de Calvin, a convivência deles não opera com dinâmicas de apreensão, nem da utilidade, nem com referência a papéis pré-determinados ou hierarquias; a amizade é, talvez, um dos últimos redutos da experiência desfuncionalizada que, como o jardim, convida a descobertas exuberantes e ímpares.

\section{Hora de dormir}

Exploramos com Calvin e Haroldo algumas particularidades e potencialidades das crianças e dos animais como personagens. Ficou-nos essa coexistência dos dois como um terreno de intermitências: se há muito em comum, há também vastas ravinas de uma diferença intransponível - o que não é o mesmo de intransitável, e a ficção parece-nos uma boa 
modalidade de incursão por outridades. Perpassou este estudo a questão do humor, tom que modula e tem o condão de dispor favoravelmente quanto ao inesperado e ao diferente. Concluímos ecoando Maciel:

\footnotetext{
Não obstante a subjetividade animal engendrada pela linguagem poética esteja, como foi dito, na ordem da invenção, o animal que esta faz advir através de sons, imagens, movimento e silêncio pode ser dado a ver, para além da condição neutra do pronome it, como um ele, um ela, um eu. Levando-nos ao reconhecimento da animalidade que nos habita. (MACIEL, 2011, p. 98)
}

Com alguns ajustes, essas palavras não estariam fora de lugar também com relação às crianças fabuladas, que abrem condições para a consideração tanto do olhar desses pequenos outros quanto para uma disponibilidade maior dos adultos para as zonas de alteridade que lhes são constitutivas. Nesse quadro, como as tirinhas, a literatura pode ser espaço/dinâmica de entrada-em-alteridade, ou ao menos de abertura a isso, o que, sem constrangi-la a imperativos pedagógicos ou morais, talvez seja uma de suas grandes potências éticas.

\section{Referências}

BUTLER, Judith. Bodies that matter. In:

Bodies that matter: on the discursive limits of sex. New York: Routledge, 1993, p. 21-50.

DERRIDA, Jacques. O animal que logo sou (a seguir). Trad. Fábio Landa. São Paulo: Ed. Unesp, 2002.

GREGORIN FILHO, José Nicolau. Literatura infantil: possibilidades de leitura. In: COENGA, Rosemar (org.). Leitura e literatura infanto-juvenil. Redes de sentido. Cuiabá: Carlini e Caniato, 2010, p. 13-24.

HUNT, Peter. Definição de Literatura Infantil. In: Crítica, teoria e literatura infantil. Trad. Cid Knipel Moreira. São Paulo: Cosac Naify, 2010, p. 73-101.

LAJOLO, Marisa. Literatura infantil brasileira e estudos literários. Estudos de Literatura Brasileira Contemporânea, n. 36. Brasília, jul.-dez. 2010, p. 97-110.

LAUWE, Marie-José Chombart de. O Meio Natural e o Simbolismo dos Elementos. In: . Um outro mundo: a infância. Trad. Noemi Kon. São Paulo: Edusp/Perspectiva, 1991. (Col. estudos, v. 105)

MACIEL, Maria Esther. Poéticas do animal. In: (org.) Pensar/escrever o animal. Ensaios de zoopoética e biopolítica. Florianópolis: Editora da UFCS, 2011.

NIĖRES-CHEVREL, Isabelle. Une dénomination problématique. In: Introduction à la littérature de jeunesse. Paris: Didier Jeunesse, 2009, p. 13-30.

PRINCE, Nathalie. Deux stéreotypes de la littérature d'enfance: l'animal et l'enfant. In: . La littérature de jeunesse. Pour une théorie littéraire. 2. ed. Paris: Armand Colin, 2015, p. 93-104.

RAMOS, Paulo. Tira ou tirinha? Um gênero com nome relativamente instável. Estudos Linguísticos, São Paulo, v. 42, n. 3, p. 1281-1291, set.-dez. 2013.

Piadas e tiras cômicas: semelhanças entre gêneros. Revista USP, São Paulo, n. 88, p. 50-59, dez./ fev. 2010-2011.

SINGER, Paul. Liberação animal. Trad. Marcelo Brandão Cipolla; Marly Winckler. São Paulo: Martins Fontes, 2010.

WATTERSON, Bill. Os dias estão todos ocupados: as aventuras de Calvin e Haroldo. Trad. Alexandre Boide. São Paulo: Conrad Editora do Brasil, 2011. 
Existem tesouros em todo lugar: as aventuras de Calvin e Haroldo. Trad. Alexandre Boide. São Paulo: Conrad Editora do Brasil, 2013. ; CHRISTIE, Andrew. An Interview With Bill Watterson. s/d. Disponível em: <http://bob.bigw.org/ch/interview.html>. Acesso em: 21 set. 2018. 